\title{
Clustering Local Tourism Systems by Threshold Acceptance
}

\author{
Joseph Andria ${ }^{1}$ and Giacomo di Tollo ${ }^{2}$ \\ 1 Dip. di Scienze Economiche, Aziendali e Statistiche, University of Palermo, Italy \\ joseph.andria@unipa.it \\ 2 Dipartimento di Management, Universitá Ca' Foscari,Venezia, Italy \\ giacomo.ditollo@unive.it
}

\begin{abstract}
Despite the importance of tourism as a leading industry in the development of a country's economy, there is a lack of criteria and methodologies for the detection, promotion and governance of local tourism systems. We propose a quantitative approach for the detection of local tourism systems that are optimal with respect to geographical, economic, and demographical criteria. To this end, we formulate the issue as an optimization problem, and we solve it by means of Threshold Acceptance, a meta-heuristic algorithm which does not require us to predefine the number of clusters and also does not require all geographic areas to belong to a cluster.
\end{abstract}

\section{Introduction}

For many countries, tourism represents a consistent part of the gross domestic product, and is a key activity to develop employment in related service industries as accommodation, transportation, hospitality, and catering. The importance and multidimensionality of tourism has led to an increased attention by both academics and governments $[1,2,3,4,5]$. A particular focus has been given to modelling local government systems in order to foster tourism development and to evaluate public policies [6,7]. Recently, there have been studies aimed in grouping together tourist attractions in order to define systems whose entities contribute to create added value [8,9]. To this aim, the notion of clustering can be successfully applied to tourism, since tourist attractions may be grouped together into clusters to optimize a combination of factors in order to produce added value. Porter [10] has defined clusters as geographical concentrations of interconnected companies whose joint activity leads to a competitive advantage to its members. Clusters have a long-term impact on the local economy, and they remain active until the reason of its existence holds [11]. In the traditional analysis, clusters are either composed of businesses that produce substitute goods (horizontal clusters) or businesses that produce intermediate goods which are then assembled together (vertical clusters). In tourism instead, businesses operate in a context in which cooperation and competition co-exist, leading to the definition of diagonal clusters $[12,13]$ where businesses produce complementary goods or services and benefit from externalities specific to the tourism industry 
[14]. It has been shown that geographical areas with the strongest presence of clusters are the most successful in tourism [6]. The reason of identifying tourist clusters is twofold: fist, it is related to administrative rules that have imposed the definition of tourist clusters for regulation purposes; then, there exists some kind of tourism that implicitly define clusters, hence a definition of clusters w.r.t. constraints imposed by the nature of tourism itself may be used to foster that particular type of tourism in a given region. In our work, we are focusing on the first reason, in order to comply with some administrative rules introduced by the Italian legislation, since the Sicilian Regional Actuative Decree n. 4 - 2010 has defined a series of requirements to recognise a geographical entity as a local tourism system. A framework imposed in view of the second goal is left for future work. In this paper we introduce a method that is able to define clusters in a given geographical area without any assumption nor constraints with respect to the administrative aggregate or the number of clusters: we define the problem as an optimisation problem and we solve it by means of a meta-heuristic approach referred to as Threshold Accepting (TA). We want to stress out that our focus is on the application of a metaheuristic to the problem at hand: an exhaustive experimental comparison about several metaheuristics is out of the scope of this paper, and will be left for further works. Please notice that we do not predefine the number of clusters and also allow areas not to belong to any cluster. Our goal is to show that our procedure produces clusters that are able to explain the tourist features of a region. The resulting geographical regions (clusters) have to have the following features $[15,16]$ :

1. clusters have to represent a tourist destination network in a well-defined area, where a small number of tourism sites are located and visitors can access them by a one-day trip;

2. clusters have to be a tourism complex, which includes various multiple tourism attractions (accommodations, restaurants, amusement parks etc.).

The rest of the paper is organised as follows: Section 2 gives us an overview about the related literature on the topic; section 3 describes our formulation of the problem. Section 4 outlines our experimental analysis, before concluding and stressing out possible future research on section 5 .

\section{Related Works}

An area's tourist development cycle can be divided into diverse phases [17]: in a first phase, referred to as discovery phase, a small number of tourists discover the area, making their own travel arrangements, following irregular journey patterns; then, when the number of visitors increases, the local communities (i.e., the economic actors belonging to the cluster) start to provide services for the tourists mass (local initiative phase). In the following phase (referred to as institutionalisation), the area's specific features are recognized by the tourist potential visitors, and the area gains popularity. Finally the area may enter in either a consolidation or a stagnation phase, due to changes in the visitor preferences, 
emergence of new tourism districts etc. The public sector plays a crucial role in this cycle (above all in the last phases) by promoting sustainable development, thus hindering a possible decline [18]; hence there are more and more laws and guidelines concerning the definition of tourist districts and measures to promote them. In Italy the legislator has defined the role of local tourism systems in the Legislative Decree n. 79-2011, which entitles the Italian regions to recognise and promote these systems as part of their policies and management tasks. Hence, a method to identify local systems have to be developped. Identifying clusters is relevant not only for regulatory purposes. Indeed the need of clustering a given geographical area is inherent to some kinds of tourism itself. For instance, when taking into account drive tourism, it has been shown that the distance of 320 miles (roundtrip) can be identified as a transition point between a single destination and a multidestination travel [19]. A local authority willing to promote drive tourism, needs to consider this information in order to create clusters in which the pairwise distance between municipalities in a cluster does not exceed this distance. On the other hand, the distance between municipalities belonging to different clusters should always be bigger than this threshold. Some work on partitioning a region in tourist districts exists in the literature. [9] defined a standard for tourist zones, and used it to divide a Korean region into five zones; [8] use network analysis to understand which municipalities are apt to be part of a rural tourism districts in Jangheung-gun and Jeollanam-do (Korea). Most work is based upon the granularity of a region [20,21], but some authors have shown that it is not suitable to work at this level of granularity [22] since it imposes binding constraints over the cluster composition. We end this section by noticing that the idea of applying intelligent algorithms to tourism clustering problems is still not exploited: the few existing approaches [23,24] aim to find attractive areas rather than clustering or partitioning; they are more focused on web and social-network based content, and use data which cannot be reconducted to the ones at hand, hence a comparison is not possible.

\section{Problem Formulation}

A geographical area consists of territorial units (municipalities), and can be represented by a non oriented graph whose vertices are the territorial units. The graph is denoted

$$
G=(V, E)
$$

where $V=\left\{1, \ldots, n_{U}\right\}$ is the set of vertices corresponding to the $n_{U}$ territorial units and $E=\left\{1, \ldots, n_{E}\right\}$ is the set of edges representing the pairwise distance between territorial units. To each vertex $i$ is associated a value $w_{i}$ representing the attractiveness of the territorial unit (see what follows). To each edge $k$ connecting vertices $h_{k}$ and $t_{k}$ is associated a value $e_{k}$ corresponding to the inverse distance between $h_{k}$ and $t_{k}$. In our work we aim at identifying clusters of vertices forming tourism systems. To this goal, we have to introduce the concept of attractiveness: The attractiveness of a geographical entity can be defined as its capacity to contribute to the tourist well-being (see for instance $[25,26,27]$ ). 
Following [26], we translate this concept into a measure for the aggregate attractiveness as perceived by tourists. A geographical area can offer a number of features such as hotels, outdoor accommodations and bed and breakfast, restaurants, night clubs, travel agencies, tourist guides, cultural life, transportation infrastructure etc. The potential of a given unit to attract tourism is a function of these features. Features taken into account in our work are detailed in Tab. 1 (see what follows). Each feature is assessed by the quantity of homogeneous elements offered by all operators working in a given territorial unit (i.e. beds assess the receptiveness, number of private and public transportation companies assessing the local access and mobility, and so on). Let $P_{i}$ be the tourist presence (i.e., the quantity of nights spent by tourists in accomodation facilities belonging to territorial unit $i$ ) and $p_{i}=P_{i} / \sum_{l \in V} P_{l}$ indicate the relative tourist presence of geographical entity $i$ w.r.t. the whole region taken into account. To measure the potential of a feature $j$ in a territorial unit $i$ we introduce $S_{j i}$ as the value of feature $j$ in a given territorial unit $i$. The ratio $S_{j i} / \sum_{\ell \in V} S_{j \ell}$ represents the relative frequency of feature $j$ in the territorial unit $i$. Let $n_{F}$ be the number of features considered. The attractiveness $w$ of the territorial unit $i$ is measured by

$$
w_{i}=\sum_{k=1}^{n_{F}} \frac{S_{k i}}{p_{i} \sum_{\ell=1}^{n_{U}} S_{k \ell}} \quad i=1, \ldots, n_{U} .
$$

By aggregating territorial units in clusters, we want to create aggregates whose attractiveness is bigger than the sum of attractiveness of its components. The attractiveness of cluster $p$ can be computed as

$$
v_{p}=\sum_{i \in V_{p}} w_{i}+\sum_{c \in E_{p}}\left(w_{h_{c}}+w_{t_{c}}\right) e_{c}
$$

where $V_{p}$ and $E_{p}$ are respectively the sets of vertices and edges forming cluster (local system) $p$, with $h_{c}$ and $t_{c}$ being endpoints of edge $c$. The second term represents the gain obtained by aggregating territorial units. The overall value associated to a given clustering can be written as:

$$
\left.\Phi(y)=\sum_{\substack{i=1 \\ y(i) \neq 0}}^{n_{U}} w_{i}+\sum_{k=1}^{n_{E}} \delta_{y\left(h_{k}\right), y\left(t_{k}\right)}\left(w_{h_{k}}+w_{t_{k}}\right)\right) e_{k}
$$

where $y$ is an array of length $n_{U}$ with values $y(i) \in\{0,1, \ldots, K\}$ indicating the local system (cluster) to which the vertex $i$ belongs. The municipalities with same value $y(i)$ belong to the same cluster. The symbol $\delta$ is the Kronecker delta. Since $G$ is symmetric, we assume $n_{E}=\frac{\left(n_{U}\right)\left(n_{U}-1\right)}{2}$. By maximising Eq. (3) we solve the Unconstrained Tourism Cluster Problem.

\section{The optimization problem}

Our goal is to identify a clustering which maximizes the value of $\Phi(y)$ in Eq. (3). As a benchmark we have chosen the region Sicily, and our goal is to cluster its 390 
municipalities. For the purpose of the application, the attractiveness weights of the municipalities are estimated based on the features given in Table 1 by using equation (1) where $S_{k i}$ represents, in turn, for the $i-t h$ territorial unit, the "cultural heritage goods", the "number of companies operating in transport", the "number of beds of all the receptive structures", etc. Data refers to the period 1998-2002. The constraints to be taken into account are specific to the geographical region under consideration. To comply with the guidelines provided by the Sicilian Regional Actuative Decree n.4 -2010 [28] and in order to be officially recognised, a tourist district has to satisfy the following constraints:

1. Its population has to be no smaller than 150.000 residents;

2. Its receptive capacity must be no lower than 7.500 beds;

3. It has to show commercial activity by having at least one commercial shop per 350 residents.

Moreover we introduce an upper bound $n_{K}$ for the number of local systems. Adding these constraints to Eq. (3) leads to the Constrained tourism clustering problem, whose formulation is the following:

$$
\begin{gathered}
\max \Phi(y) \\
\sum_{k \in V_{p}} S_{2, k} \geq 150.000 \quad p=1, \ldots, K \\
\sum_{k \in V_{p}} S_{5, k} \geq 7.500 \quad p=1, \ldots, K \\
\frac{\sum_{k \in V_{p}} S_{2, k}}{\sum_{k \in V_{p}} S_{9, k}} \geq 350 \quad p=1, \ldots, K \\
K \leq n_{K}
\end{gathered}
$$

Table 1. Overall features statistics. Data refer to the whole region Sicilia, over the period 1998-2002.

\begin{tabular}{l|ccccc}
\hline & \multicolumn{3}{|c}{ Mean Median } & Std & Skewness Kurtosis \\
\hline Municipalities area $\left(\mathrm{km}^{2}\right)$ & 66.01 & 37 & 79.82 & 2.64 & 9.03 \\
Population & 12,914 & 4,713 & 40,537 & 12.15 & 178.83 \\
Cultural heritage goods & 0.98 & 0 & 3.50 & 11.16 & 161.38 \\
Transport & 41.98 & 15 & 139.40 & 10.22 & 119.31 \\
Beds in Hotels, B\&B..., & 461.15 & 47 & 1215.74 & 4.47 & 23.44 \\
Beds in Hospitals & 48.78 & 0 & 312.29 & 11.32 & 137.54 \\
Sport, Cultural activity & 47.19 & 17 & 162.97 & 11.22 & 148.03 \\
Financial intermediaries & 25.85 & 6 & 107.27 & 11.15 & 144.36 \\
Commercial Businesses & 435.88 & 135 & 1603.42 & 11.59 & 155.82 \\
Distance from airport $(\mathrm{km})$ & 81.69 & 75.90 & 44.45 & 0.22 & -0.72 \\
\hline
\end{tabular}


We are solving this optimization problem by using a particular local search technique, Threshold Accepting [29,30], which is a trajectory method whose pseudo-code is given in Algorithm 1.

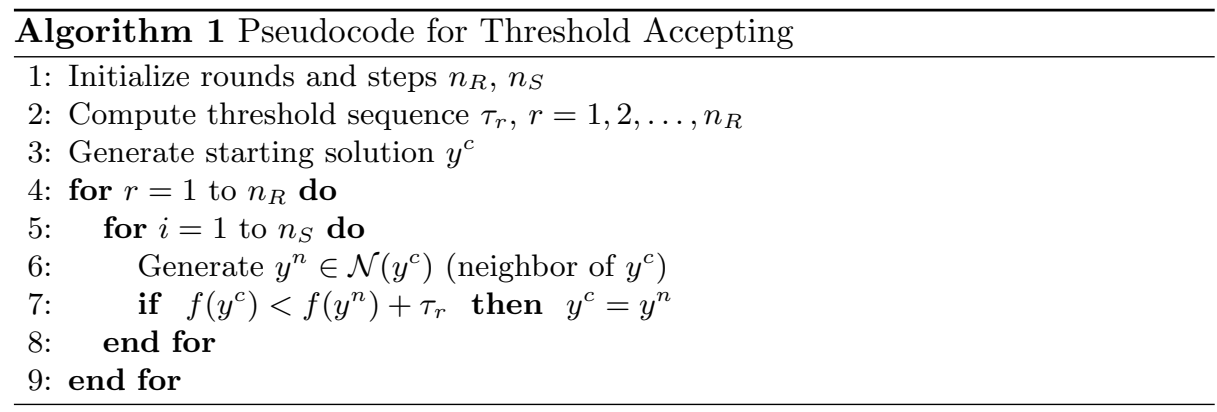

Statement 7 allows the algorithm to escape local maxima by accepting solutions which are worse than the current one, in which the worsening is not bigger than a given threshold $\left(\tau_{r}\right)$ whose value decreases to zero over execution. The values sequence is estimated by means of the empirical distribution of distances between objective values of neighboring positions. The starting solution is a $n_{U}$-sized randomly generated vector $y$ whose values represents the cluster a municipality belongs to $\left(y_{i} \in\left\{0,1, \ldots, n_{K}\right\}, \forall i\right)$. A neighboring solution is obtained by randomly picking an element of the vector (i.e., choosing a municipality) and changing its associated value (cluster) to a randomly chosen integer between 0 and $n_{K}$. Constraints are taken into account by adding a penalty term to the objective function in case of violation. Due to the non deterministic nature of the solution, the algorithm is restarted, and the best result represents the solution to the problem. A discussion about the quality of such solutions can be found in [31]. A more detailed description of the implementation of Threshold Accepting can be found in $[32,33]$.

\section{Empirical Results}

The aforementioned Sicilian Regional Actuative Decree n. 4 - 2010 has defined a series of requirements to recognise a geographical entity as a local tourism system. According to these requirements, a number of geographical entities have been classified as local tourism systems. These local systems (referred to as tourist districts) have been determined by administrative and political procedures. This section aims to compute the clusters with our model, and compare their behaviour to the tourist districts. The goal is to understand whether our approach could lead to results that are better than just considering districts and verifying some administrative rules. Hence, we solve the Constrained Tourism Clustering Problem by threshold accepting, and we compare the results with the tourist districts defined by the Regione Sicilia. The optimisation algorithm is 
implemented in Matlab R2007a and is available upon request. Figure 1 shows the Tourist Districts (a) along with clusters that have been obtained with TA by solving the Constrained Tourism Clustering Problem (b) and the Unconstrained Tourism Clustering Problem (c).

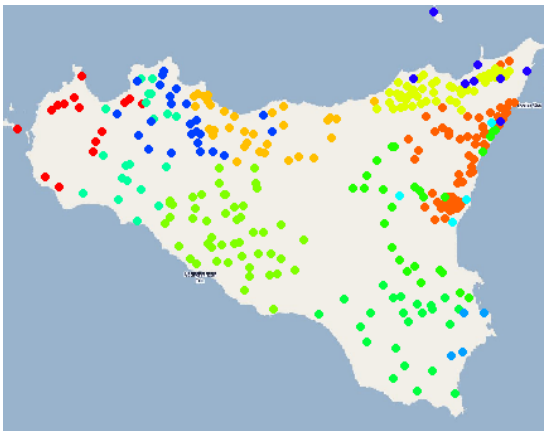

(a) Tourist Districts.

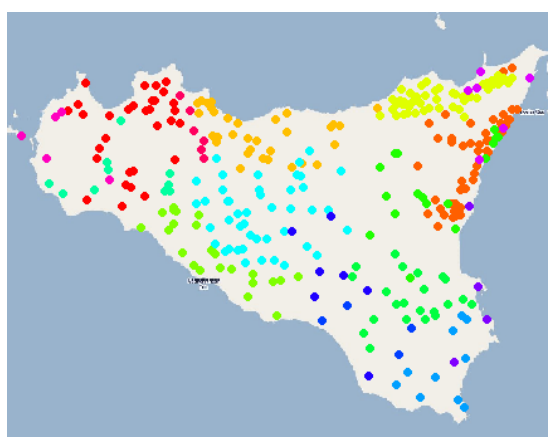

(c) TA, Unconstrained Tourism Clustering Problem.

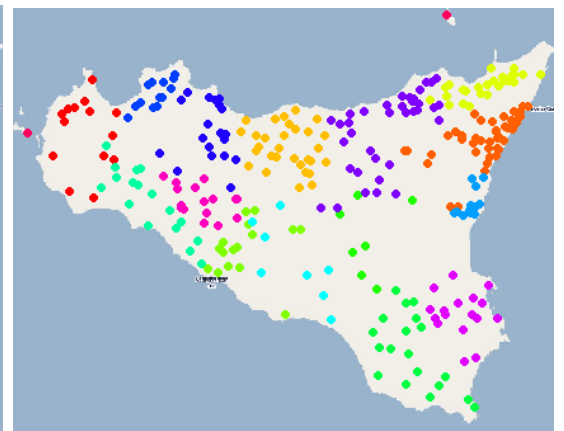

(b) TA, Constrained Tourism Clustering Problem.

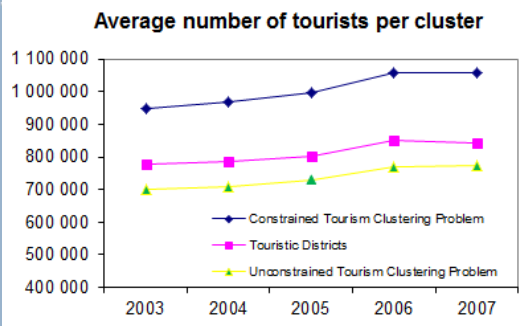

(d) Average partition's number of visitors

Fig. 1. Comparison between existing tourist districts (a) and clusters obtained by TA (b)(c), with corresponding out-of-sample number of tourists per year

The algorithm has been executed over data stemming from the period 19982002. In order to assess the performances of the obtained clusters, we are computing the number of tourists that have visited these clusters during the years 2003-2007 [34], so this assessment is a true out-of-sample analysis. Statistics about the tourist stays are reported on table 2 .

Since Threshold Accepting is not deterministic, a first analysis is aimed to know whether the algorithm is robust w.r.t. different runs. To this goal, we have implemented the partition-distance defined by [35]: applying two different clustering methods on the same set of elements $N$, we obtain two partitions $P_{0}$ and $P_{1}$. The partition-distance $D\left(P_{0}, P_{1}\right)$ is the minimum number of elements 
Table 2. Tourist Overnight Stays. Data refers to the whole Sicily over years 2003-2007.

\begin{tabular}{l|ccccc}
\hline & $\mathbf{2 0 0 3}$ & $\mathbf{2 0 0 4}$ & $\mathbf{2 0 0 5}$ & $\mathbf{2 0 0 6}$ & $\mathbf{2 0 0 7}$ \\
\hline Mean & 33,724 & 34,233 & 35,183 & 37,371 & 37,441 \\
Median & 1,153 & 1,210 & 1,524 & 1,631 & 1,641 \\
Std & 116694 & 119396 & 120711 & 126798 & 125559 \\
Skewness & 6.25 & 6.27 & 6.11 & 6.08 & 6.06 \\
Kurtosis & 47.10 & 47.03 & 44.04 & 43.35 & 43.23 \\
\hline
\end{tabular}

that must be deleted from $N$ so that the two induced partitions are identical. We have run our TA 30 times to solve our problem, computing the pairwise partition distance $D\left(P_{i}, P_{j}\right), 1 \leq i \leq j \leq 30$, and then computing the mean and standard variation over the obtained values. Results are shown on table 3 , along with statistics for the cardinality of clusters, execution time and the objective function. Values show us that the algorithm's results are rather robust, so we will continue our analysis by using the results of a randomly chosen run, without loss of generalisation.

Table 3. Statistics about the results obtained by TA, 30 runs

\begin{tabular}{l|c|c|c|c|c|c|c|c|c|}
\cline { 2 - 8 } & \multicolumn{2}{|c|}{ Cardinality } & Distance & \multicolumn{2}{c|}{ Time (sec) } & \multicolumn{2}{c|}{ OF } \\
\hline & Mean & Var & Mean & Var & Mean & Var & Mean & Var \\
\hline Tourist Districts (no TA) & 16 & - & - & - & - & - & 135.82 & - \\
Constrained Tourism Clustering & 12 & 2.18 & 14.82 & 3.48 & 106.03 & 12.01 & 192.98 & 377.86 \\
Unconstrained Tourism Clustering & 16 & 1.03 & 12.51 & 3.02 & 98.16 & 9.38 & 195.83 & 239.38 \\
\hline
\end{tabular}

We remark that the value of the objective function we want to maximise is higher when using our approaches (for both constrained and unconstrained formulations) than the one computed on the original Tourist Districts. We remark also that in the problem formulation we impose an inequality constraint $\left(4^{\prime \prime \prime \prime}\right)$ in order to limit the maximum number of clusters. This constraint is not required neither by legislative texts nor by theoretical grounds. We have taken into account the possibility of imposing it just in order to make a comparison w.r.t. the Tourist District: since there are 16 Tourist District in Sicily, we are imposing that the number of clusters to be found for the Constrained Tourism Clustering Problem shall be no greater than 16: the user just has to set an upper bound $n_{K}$ in $\left(4^{\prime \prime \prime \prime}\right)$, and this constraint is not binding for arbitrarily large values of $n_{K}$. Another remark is that the cardinality of clusters found by the Unconstrained Tourism Clustering Problem is similar to the number of Tourist Districts. When considering the Constrained Tourism Clustering Problem, the cardinality decreases to 12 for the effect of the population constraint which forbids us to have small clusters. We can also remark the implications of this difference over the out- 
of-sample number of visitors: by observing panel $(\mathrm{d})$ in Figure 1 we note that the yearly average number of visitors in the clusters obtained with the constrained tourism clustering is bigger than the one computed for the unconstrained case as well as for the tourist districts. This comes with no surprise w.r.t. unconstrained case, but it represents a good feature w.r.t. the tourist districts: it means that the tourist districts recognised by the legislative authority have a smaller number of visitors w.r.t. the ones that could be obtained by using our model based approach. Furthermore we can remark that there are tourist districts that fulfil all constraints imposed by the regulations, but whose activity related to the tourism is poor since their tourist presences are negligible and close to zero. We can see it in Figure 2, where we have plotted, for every year, all values of tourist presences for every single cluster found by the three clusters identification methods taken into account (Constrained Tourism Clustering Problems, Unconstrained Tourism Clustering Problem, and original Tourist District). We can notice that clusters having the smallest number of visitors are always the ones belonging to the Tourist Districts. This does not happen when defining the tourist districts by means of TA (Constrained Tourism Clustering): all clusters have a satisfactory number of visitors over time.

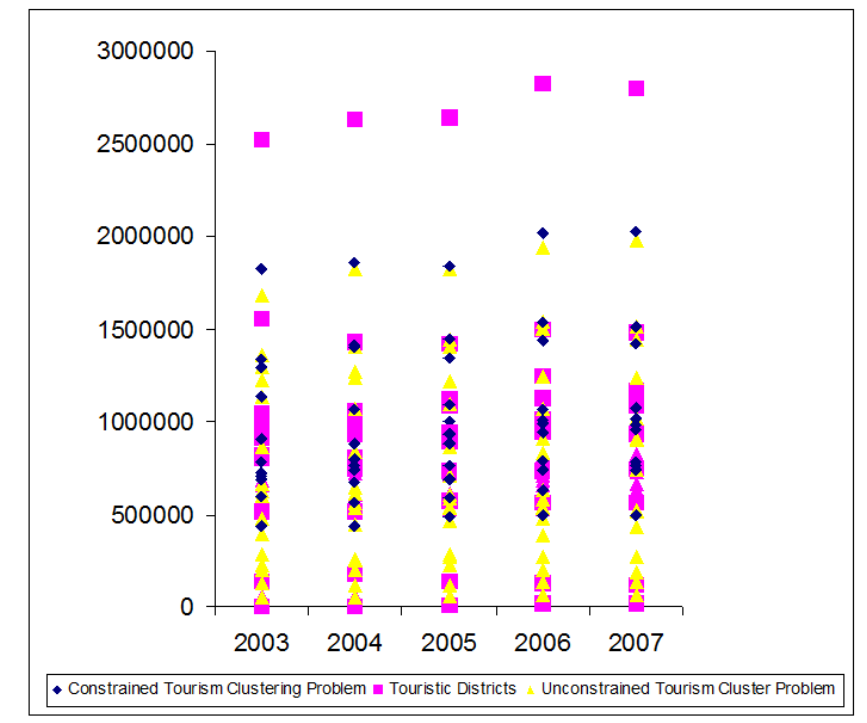

Fig. 2. Yearly presences for clusters obtained by TA and tourist districts.

We finish this section by pointing out that the clusters obtained via our TA approach are good instruments to understand the tourist behaviour of geographical regions: TA does not rely in any assumptions nor parameters to create the clusters, whose composition offers a good partitioning that takes into account the specific features of the geographic entity. Furthermore, the obtained clusters 
show a better tourist flow than existing tourist districts. We want to stress out the fact that the data taken into account for creating the partitions are the same taken into account by the legislative authority to recognise a territorial unit as a tourist district.

\section{Conclusions}

In this paper we have emphasized the role of clustering to identify local tourism systems compliant with the guidelines provided by the regulation: this issue has been modeled as an optimization problem and solved by Threshold Accepting. The optimisation problem has been solved for both the constrained tourism clustering problem and the unconstrained tourism clustering problem and the solutions have been compared with the regional tourist districts. Our approach has shown that tourist districts recognised by the local legislative authority have a smaller number of visitors than the ones obtained by using our approach. This result highlights the importance of introducing a quantitative model of competitiveness of a tourism cluster for regional development and demonstrates the importance of using real-world variables and indicators for an optimal tourist governance. Our future research will take into account different benchmarks in order to study how the algorithm behaves with respect to different geographical patterns; then, we will analyze the dynamic of clusters over time to understanding how this might affect tourist demand. Last, we will take into account the clustering problem induced by the nature of some tourist attitudes itself, such as drive turism, in order to investigate how the guidelines imposed by administrative rules may hinder or foster specific tourist flows.

\section{References}

1. Gormsen, E.: The impact of tourism on coastal areas. GeoJournal 42(1) (1997) 39-54

2. Ritchie, J., Crouch, G.: The Competitive Destination: A Sustainable Tourism Perspective. CABI Publishing Series. CABI Pub. (2003)

3. Butler, R.: The Tourism Area Life Cycle. Number v. 1 in Aspects of tourism. Channel View Publications (2006)

4. Hawkins, D., Mann, S.: The world bank's role in tourism development. Annals of Tourism Research 34(2) (2007) $348-363$

5. Macbeth, J.: Towards an ethics platform for tourism. Annals of Tourism Research 32(4) (2005) $962-984$

6. Jackson, J., Murphy, P.: Clusters in regional tourism an australian case. Annals of Tourism Research 33(4) (2006) 1018 - 1035

7. Leask, A.: Progress in visitor attraction research: Towards more effective management. Tourism Management 31(2) (2010) 155 - 166

8. Lee, S., Choi, J., Yoo, S., Oh, Y.: Evaluating spatial centrality for integrated tourism management in rural areas using $\{$ GIS $\}$ and network analysis. Tourism Management 34 (2013) $14-24$

9. Sim, I.: A study on the establishment of tourism zone and development strategic. Korean Academic Society of Culture and Tourism 4 (2002) 199-223 
10. Porter, M.: On competition. Harvard Business School Publishing, Boston (1998)

11. Brenner, T., Gildner, A.: The long-term implications of local industrial clusters. European Planning Studies 14(9) (2006) 1315-1328

12. Di Tollo, G., Tanev, S., De March, D., Ma, Z.: Neural networks to model the innovativeness perception of co-creative firms. Expert Systems with Applications 39(16) (2012) 12719-12726

13. Brandenburger, A., Nalebuff, B.: Co-opetition / Adam M. Brandenburger and Barry J. Nalebuff. 1st ed. edn. Doubleday New York (1996)

14. Yang, Y.: Agglomeration density and tourism development in china: An empirical research based on dynamic panel data model. Tourism Management 33(6) (2012) 1347-1359

15. Yabuta, M., Scott, N.: Dynamic properties of a tourism destination network. Tourism Analysis 16(4) (2011) 493-498

16. Yabuta, M., Scott, N.: A theoretical framework of the dynamic property of the tourism destination network. Technical report, the University of Queensland (2010)

17. Stansfield, C.: Atlantic city and the resort cycle background to the legalization of gambling. Annals of Tourism Research 5(2) (1978) 238 - 251

18. Butler, R.: The concept of a tourist area cycle of evolution: Implications for management of resources. Canadian Geographer / Le Gographe canadien 24(1) (1980) $5-12$

19. Hwang, Y., Fesenmaier, D.: Multidestination pleasure travel patterns: Empirical evidence from the american travel survey. Journal of Travel Research 42(2) (2003) 166-171

20. Jin, X., Weber, K., Bauer, T.: Impact of clusters on exhibition destination attractiveness: Evidence from mainland china. Tourism Management 33(6) (2012) 1429 $-1439$

21. Enright, M.: Regional clusters: What we know and what we should know. In Brcker, J., Dohse, D., Soltwedel, R., eds.: Innovation Clusters and Interregional Competition. Advances in Spatial Science. Springer Berlin Heidelberg (2003) 99129

22. Pearce, D., Tan, R., Schott, C.: Distribution channels in international markets: A comparative analysis of the distribution of new zealand tourism in australia, great britain and the usa. Current Issues in Tourism 10(1) (2007) 33-60

23. Sakai, T., Tamura, K., Kitakami, H.: Density-based adaptive spatial clustering algorithm for identifying local high-density areas in georeferenced documents. In: Systems, Man and Cybernetics (SMC), 2014 IEEE International Conference on. (Oct 2014) 513-518

24. Sakai, T., Tamura, K., Kitakami, H.: A new density-based spatial clustering algorithm for extracting attractive local regions in georeferenced documents. In: Proceedings of the International MultiConference of Engineers and Computer Scientists 2014. (March 2014) 360-365

25. Jin, X., Weber, K., Bauer, T.: Impact of clusters on exhibition destination attractiveness: Evidence from mainland china. Tourism Management 33(6) (2012) 1429 $-1439$

26. Cracolici, M., Nijkamp, P.: The attractiveness and competitiveness of tourist destinations: A study of southern italian regions. Tourism Management 30(3) (2009) $336-344$

27. Ryan, C.: The Tourist Experience. Continuum (2002)

28. Siciliana, R.: Criteri e modalità per il riconoscimento dei distretti turistici. Gazzetta Ufficiale della Regione Siciliana (2010) 
29. Dueck, G., Scheuer, T.: Threshold accepting: A general purpose optimization algorithm appearing superior to simulated annealing. J. Comput. Phys. 90(1) (August 1990) 161-175

30. Moscato, P., Fontanari, J.: Stochastic versus deterministic update in Simulated Annealing. Physics Letters A 146(4) (1990) 204-208

31. Gilli, M., Schumann, E.: Optimal enough? Journal of Heuristics 17(4) (2011) 373-387

32. Gilli, M., Winker, P.: Heuristic optimization methods in econometrics. In Belsley, D.A., Kontoghiorghes, E., eds.: Handbook of Computational Econometrics. Wiley (2009)

33. Gilli, M., Maringer, D., Schumann, E.: Numerical Methods and Optimization in Finance. Academic Press, London (2011) ISBN 978-0-12-375662-6.

34. Istat: Primo Repertorio Statistico dei Comuni della Sicilia. Sistema Statistico Nazionale (2008)

35. Gusfield, D.: Partition-distance: A problem and class of perfect graphs arising in clustering. Information Processing Letters 82(3) (2002) 159 - 164 